
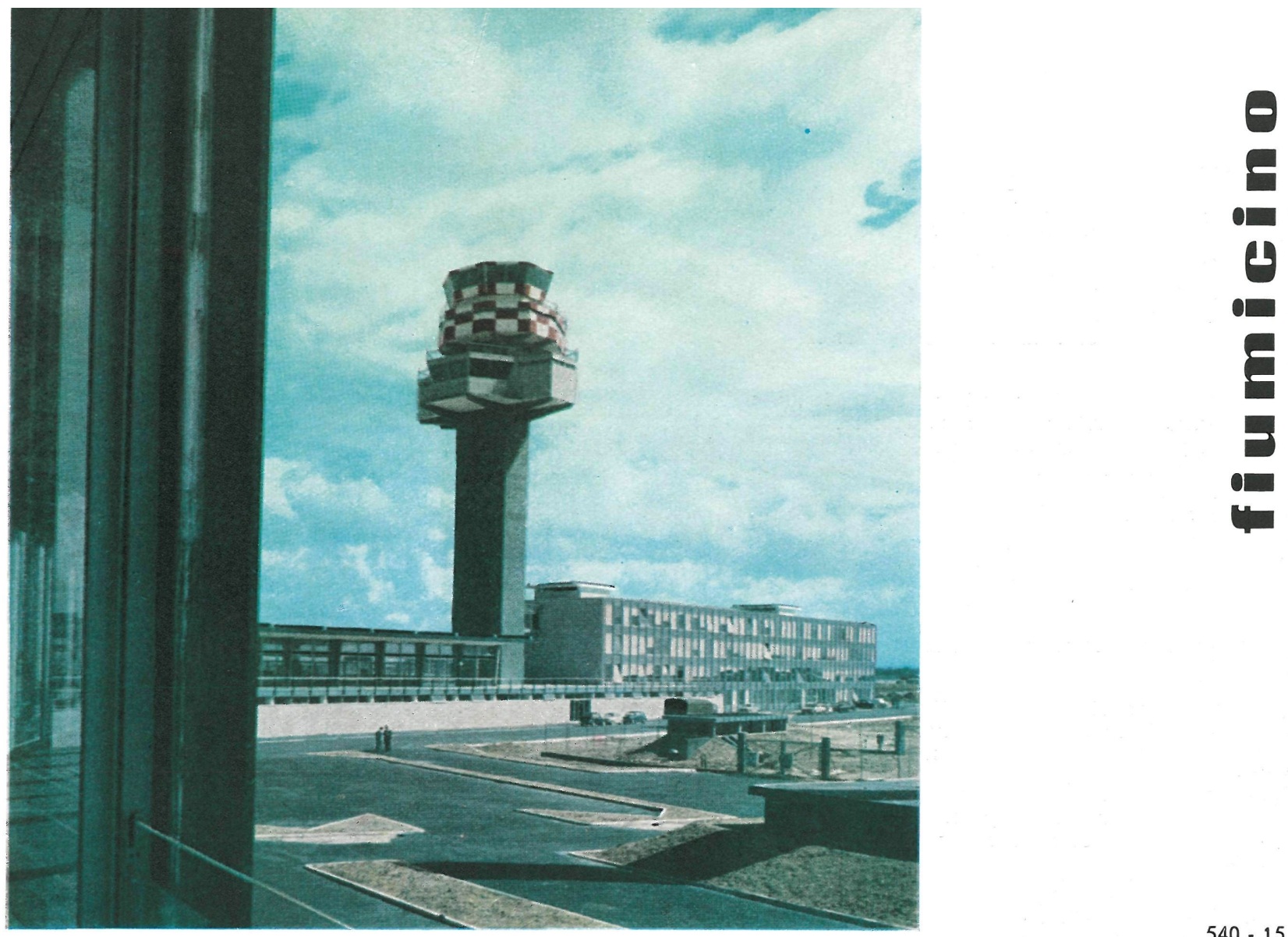

\title{
aeropuerto internacional de Roma
}

LUCCICHENTI Y MONACO, arquitectos

MORANDI, ingeniero, y ZAVITTERI, arquitecto

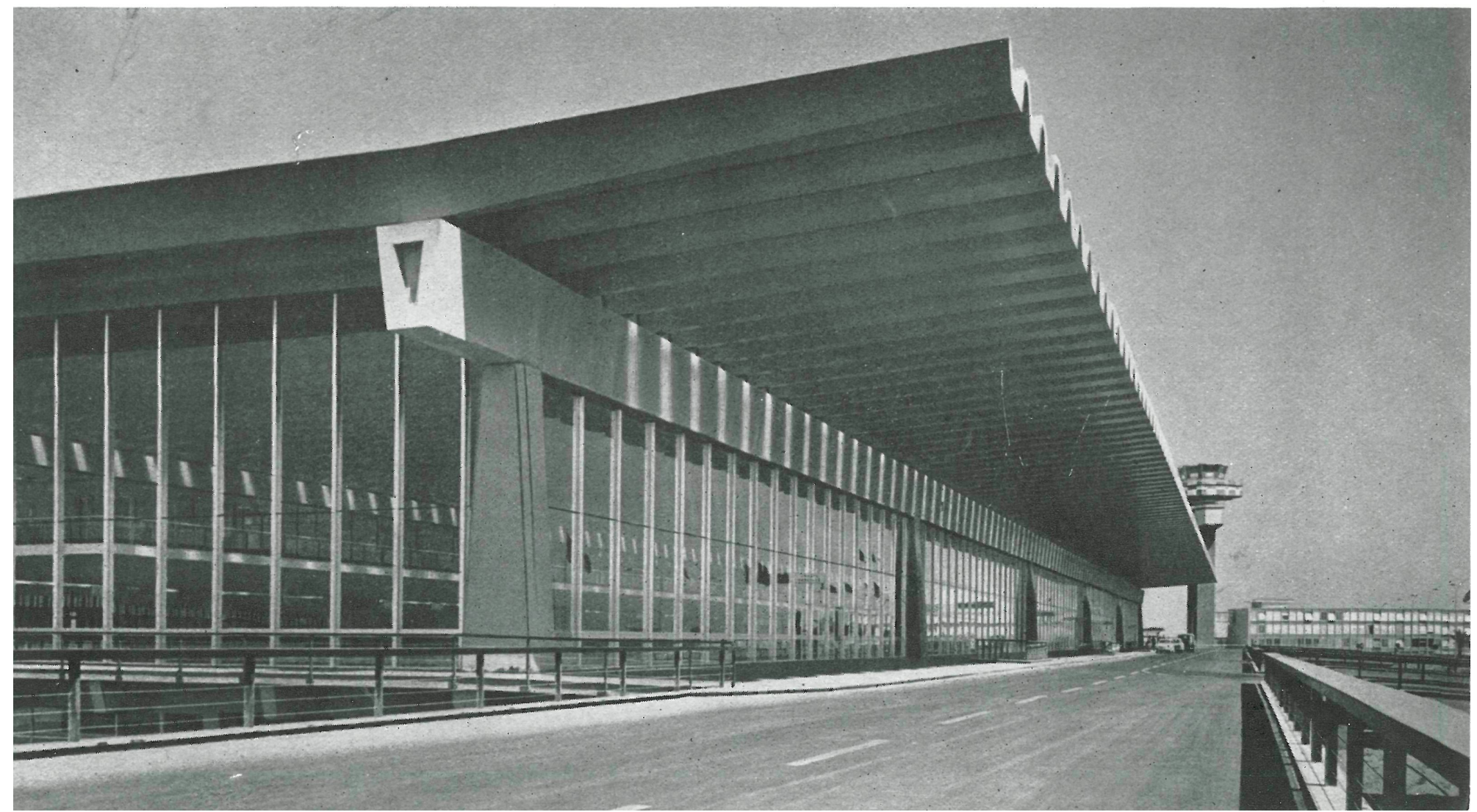




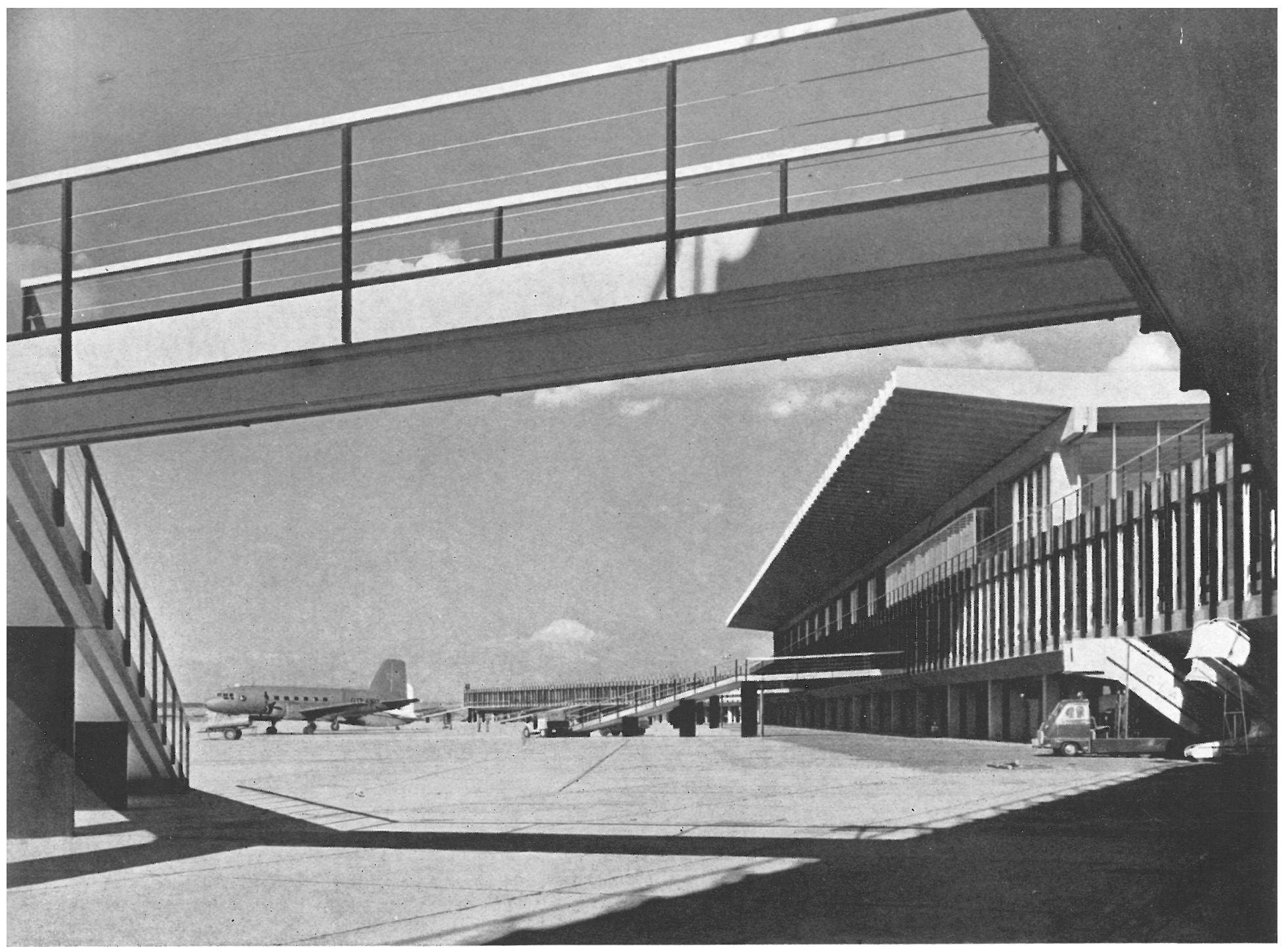

El nuevo Aeropuerto intercontinental de Roma es el producto de un proyecto elaborado, con minucioso y prolijo cuidado, a lo largo de diez años de concienzudo trabajo.

El actual edificio ha sido proyectado sobre el viejo esquema, previsto para un organismo tripartito con tres aeroestaciones independientes.

En los últimos dos años los trabajos han tomado un ritmo acelerado, y la aeroestación se ha proyectado y terminado en el tiempo récord de un año y medio escasos, con medios financieros limitados.

El edificio actual consta de un gran hall central, que contiene todos los servicios relativos al tráfico de pasajeros, control de aduanas y policía, oficinas de las compañías aéreas, tráfico de llegada, partida y tráfico de viajeros.

El servicio se ha organizado en tres niveles:

Nivel del campo: $(2 \mathrm{~m})$. Tráfico de equipajes, almacenes, servicios generales (calefacción, acondicionamiento, cocina, vestuarios...).

Nivel principal: $(6,10 \mathrm{~m})$. Tráfico de pasajeros.

Nivel de cubierta del muelle: $(10,15 \mathrm{~m})$. Tráfico de visitantes, viajeros de tránsito, restaurante y oficinas de las Compañías.

A la derecha de la aeroestación están las oficinas de asistencia de vuelo, torre de control con sus servicios y el salón para pilotos. 


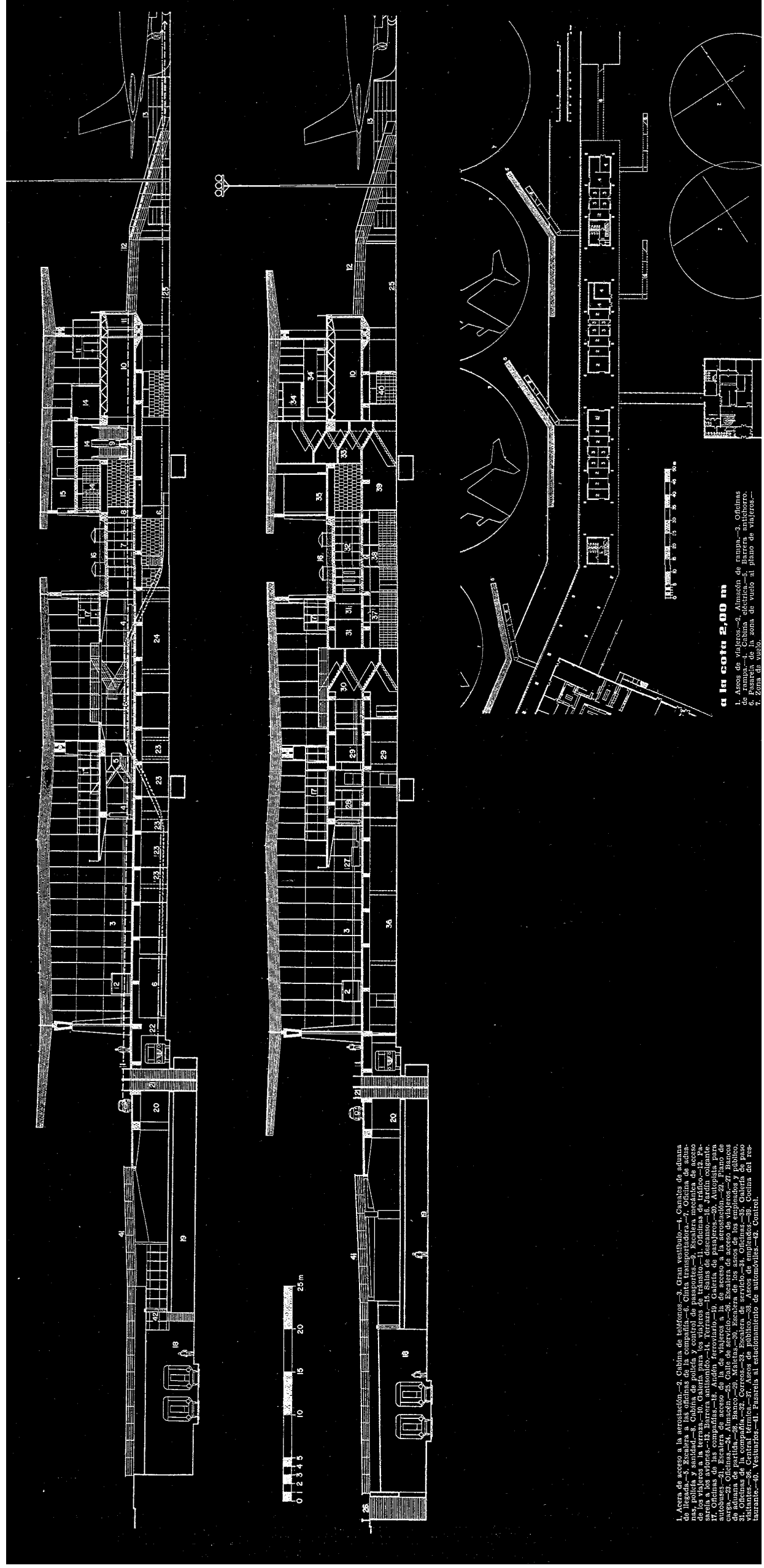




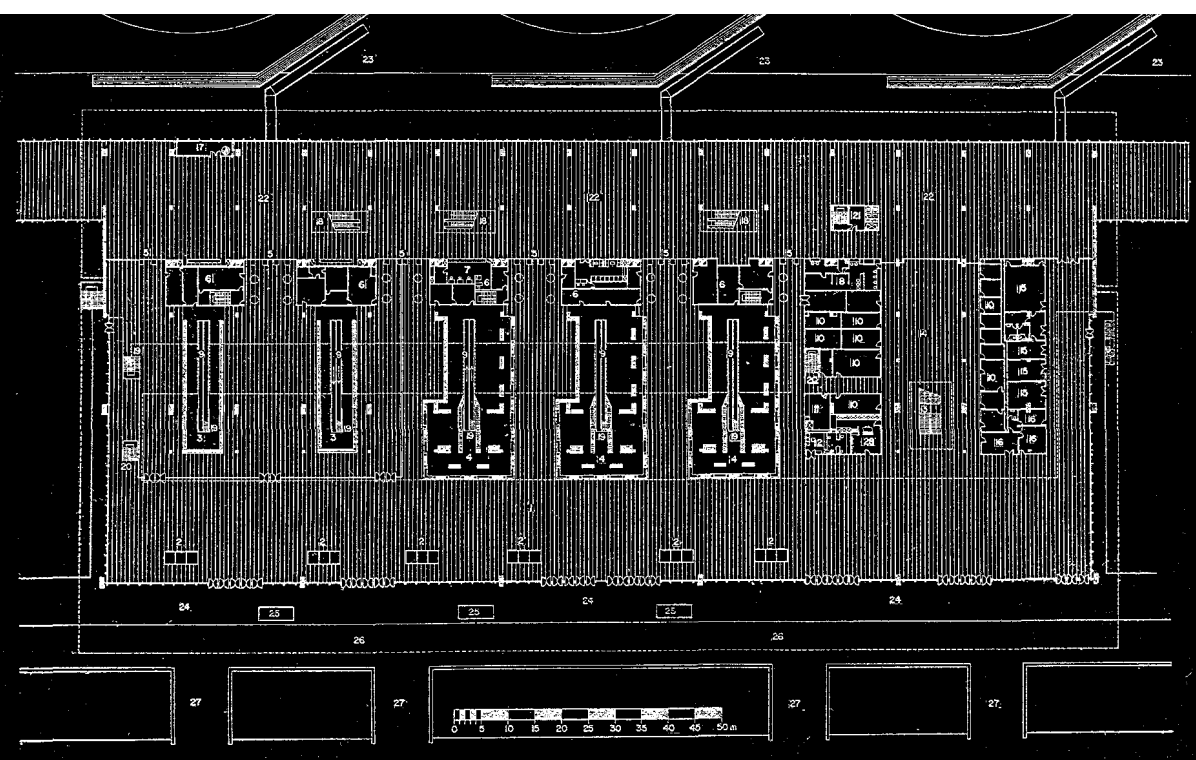

de vicieros

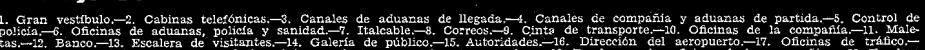

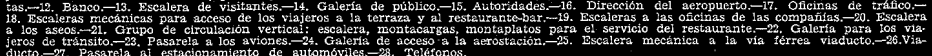

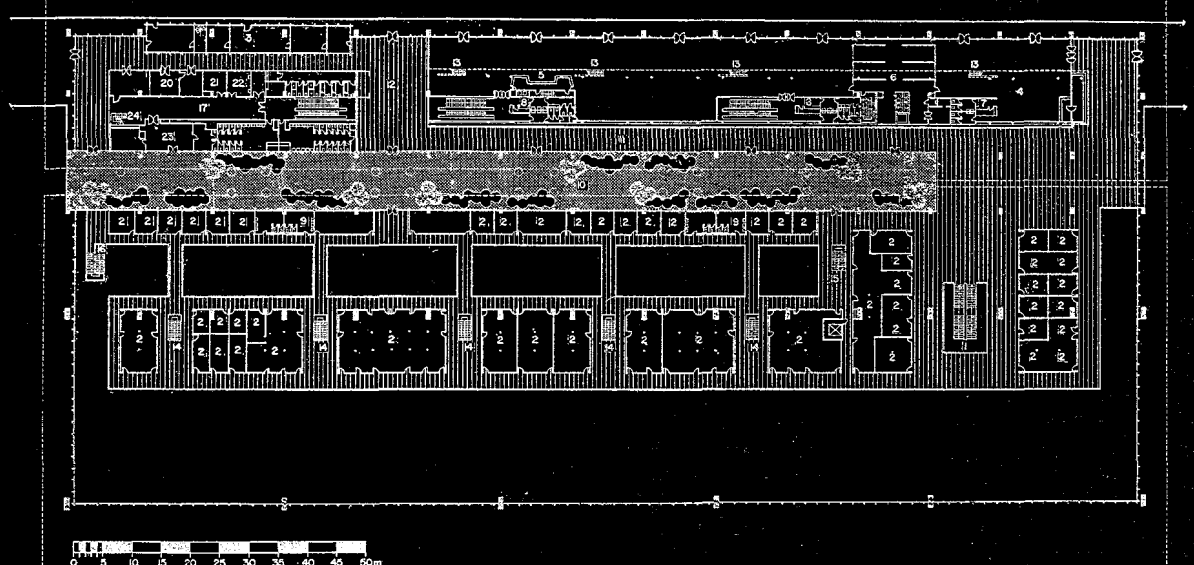

de ofteinas nestaunante is kar

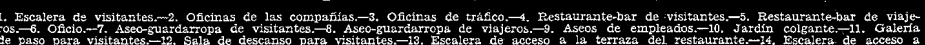

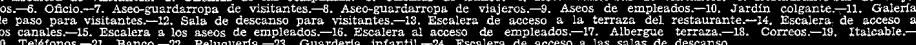

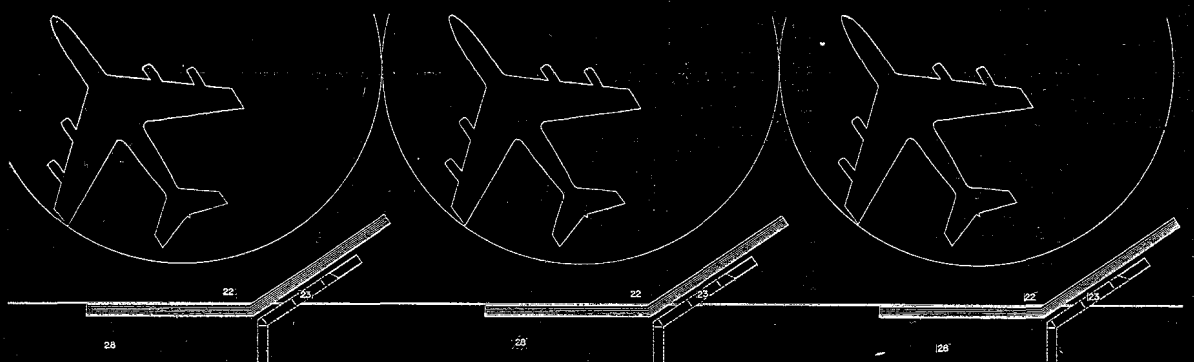

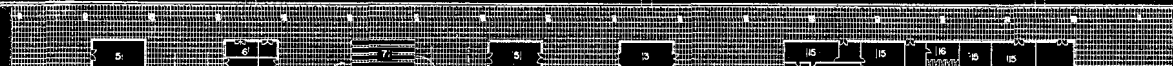

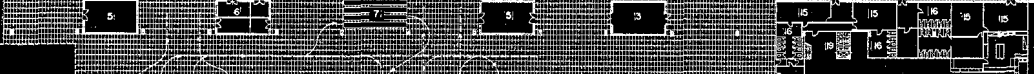

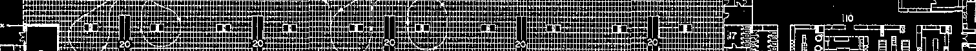

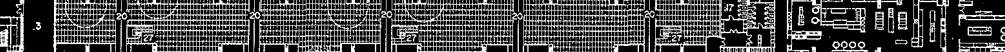
1.

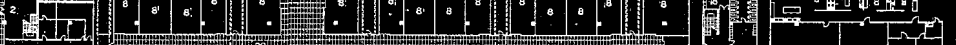

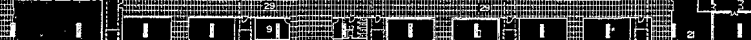
-

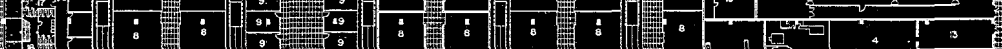

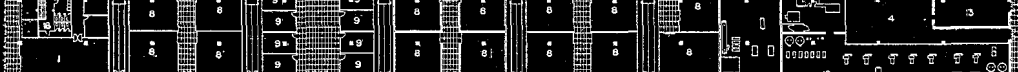
H.m. II \% $\square 260$

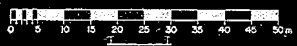

de almacenas

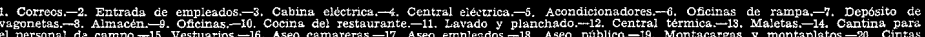




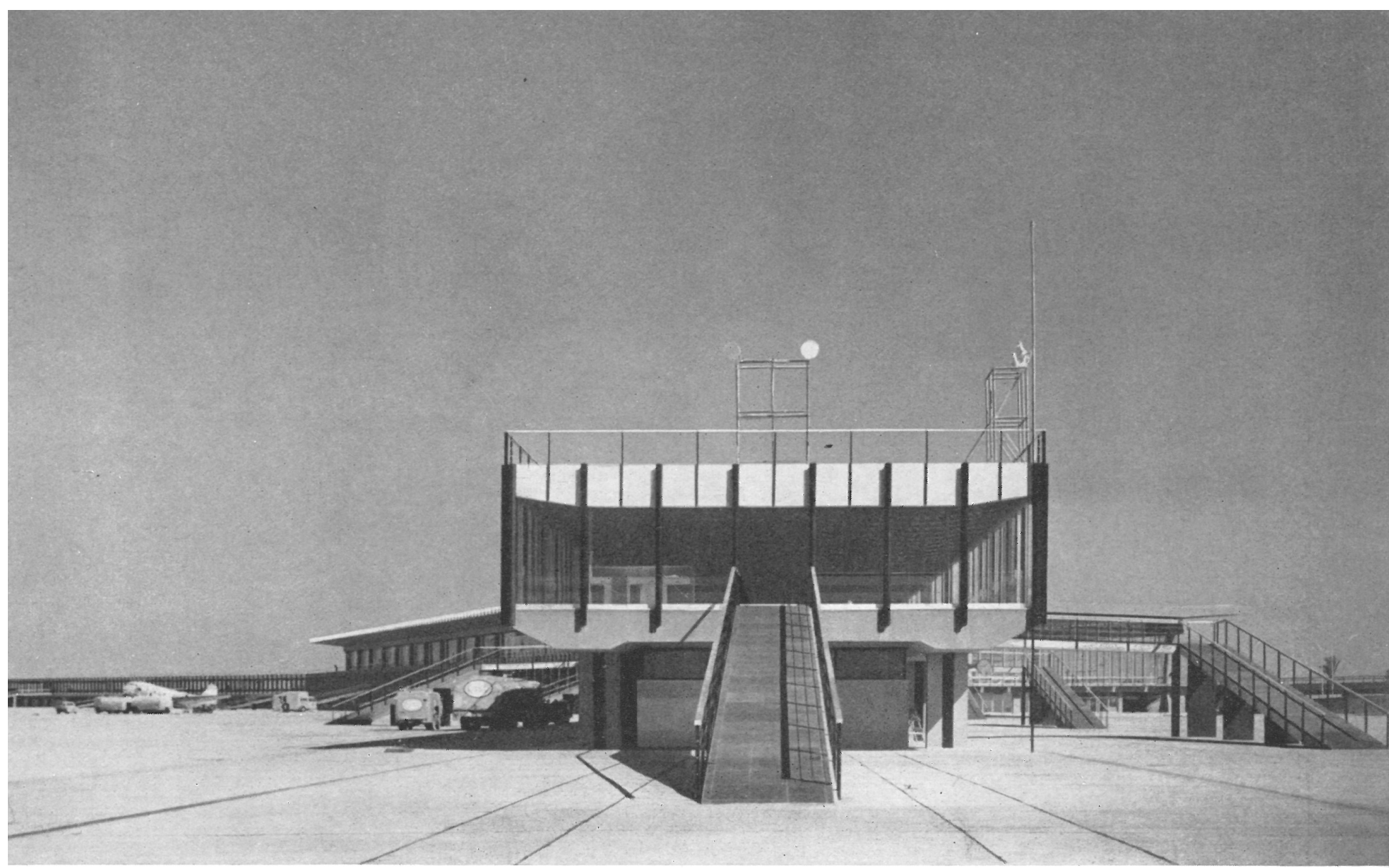

\section{Tráfico aéreo}

La disposición de las pistas permite calcular una frecuencia de movimiento (despegue y aterrizaje) cada tres minutos para cada pista. En una hora pueden despegar y aterrizar, en una pista, casi veinte aparatos.

Si suponemos que cada avión lleva un promedio de cien pasajeros, cada una de las pistas permite, con una buena organización y la correspondiente seguridad de vuelo, un movimiento de 2.000 pasajeros por hora.

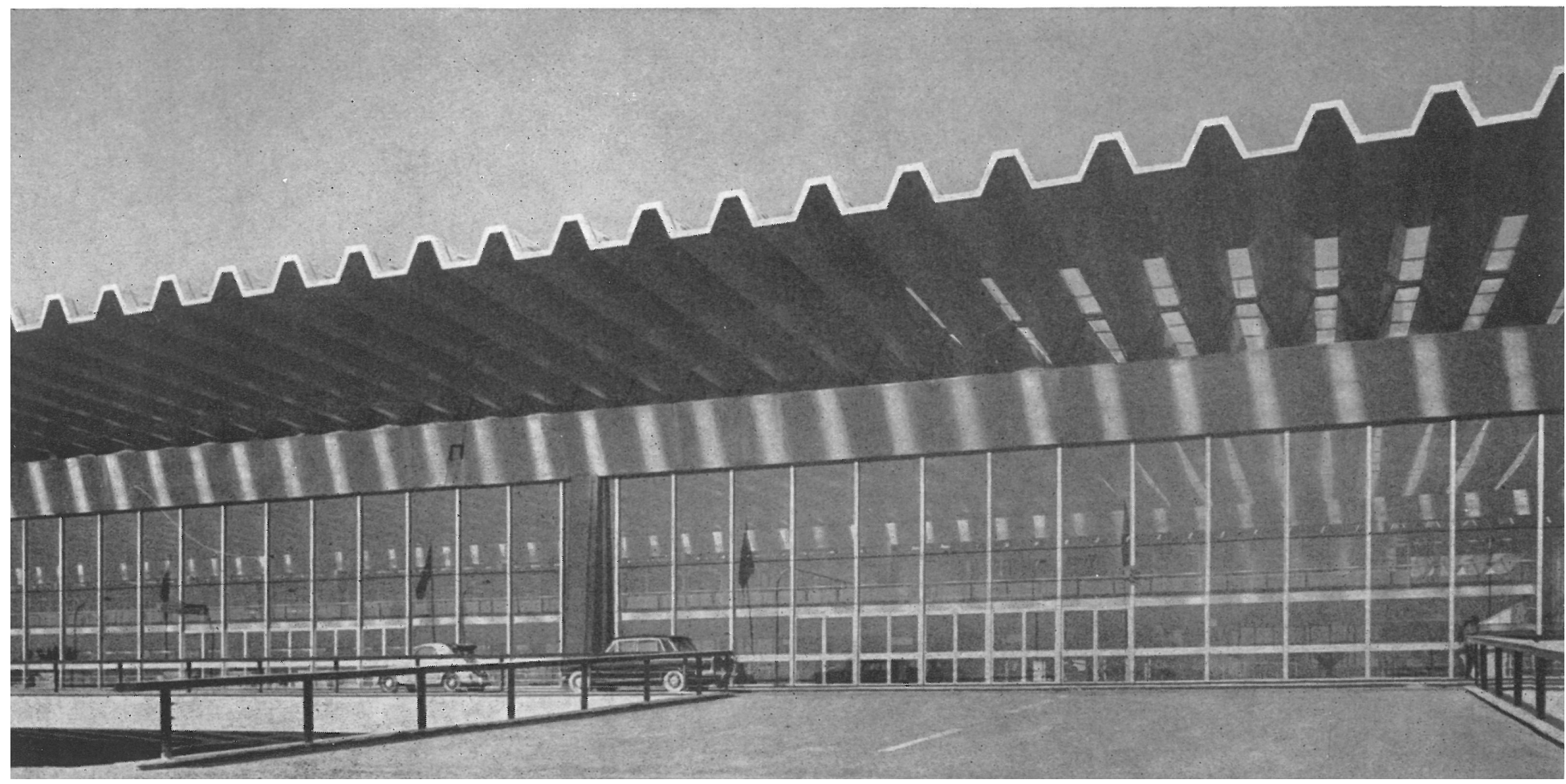




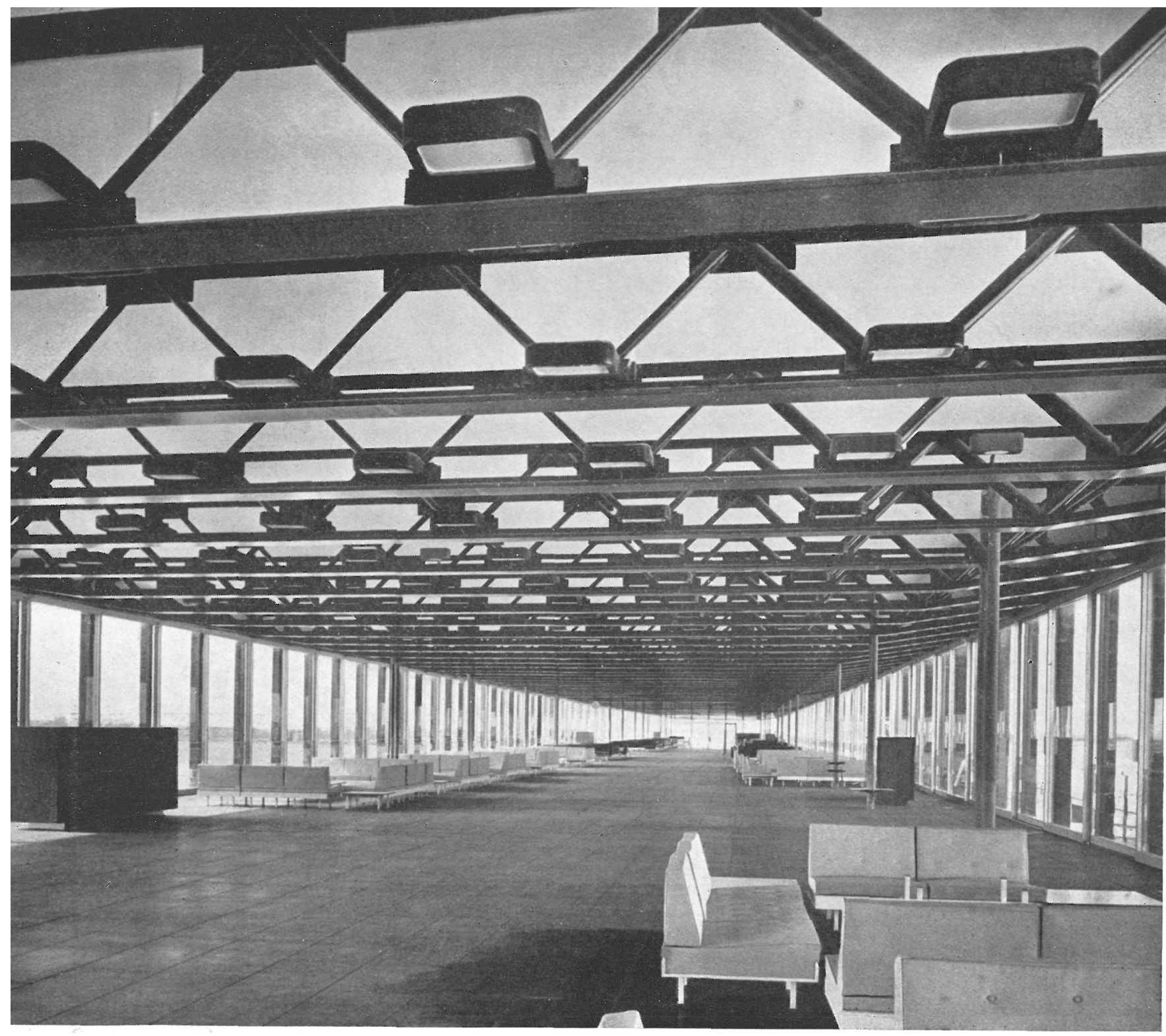

El número de los aparcamientos, resultado de la planimetría general, permite la estancia de 13 reactores y 9 aviones a hélice, teniendo presente que el círculo de maniobra de cada uno es de $80 \mathrm{~m}$ para los reactores y de $50 \mathrm{~m}$ para aviones normales, dimensiones éstas que permiten a los aparatos la aproximación o alejamiento de la aeroestación por sus propios medios.

Si los aviones son transportados, el número de estacionamientos aumenta en un $40 \%$.

\section{Tráfico de viajeros y equipajes}

El tráfico de llegada, partida y tránsito se desarrolla en la cota 6,10 m de la aeroestación. Aquí se encuentran los mostradores de las compañías aéreas, controles de aduanas, sanitarios y de policía, subidivididos en seis "canales" para partida y cuatro para llegada.

Los equipajes se transportan a la planta inferior, que se encuentra al nivel del campo y al que accede por medio de rampa. De aquí son transportados, a través de diez cintas mecánicas, a la zona de control de ađuana, en el canal correspondiente de llegada o partida, hasta llegar así al lugar donde lo espera el viajero.

Inmediatamente son transportados, por el mismo sistema, a los aviones o a los autobuses, según se trate de partida o de llegada, respectivamente.

En la cota 2 están situados los almacenes y servicios generales de las compañías (cocina, instalaciones, vestuarios y comedor del personal del campo, aseos para empleados y aseos para el público en general). 


\section{imteriores}

En la cota 6,10 se desarrolla todo el tráfico de viajeros, los cuales pueden acceder a la planta superior, por medio de tres escaleras mecánicas, donde se hallan: el restaurante para 600 personas, snack-bar, nursery, sala de descanso... En esta cota 6,10 están las tiendas, teléfonos, telégrafo, correos, bancos... y espera de viajeros. Desde aquí puede accederse, mediante 14 rampas, a los propios aviones.
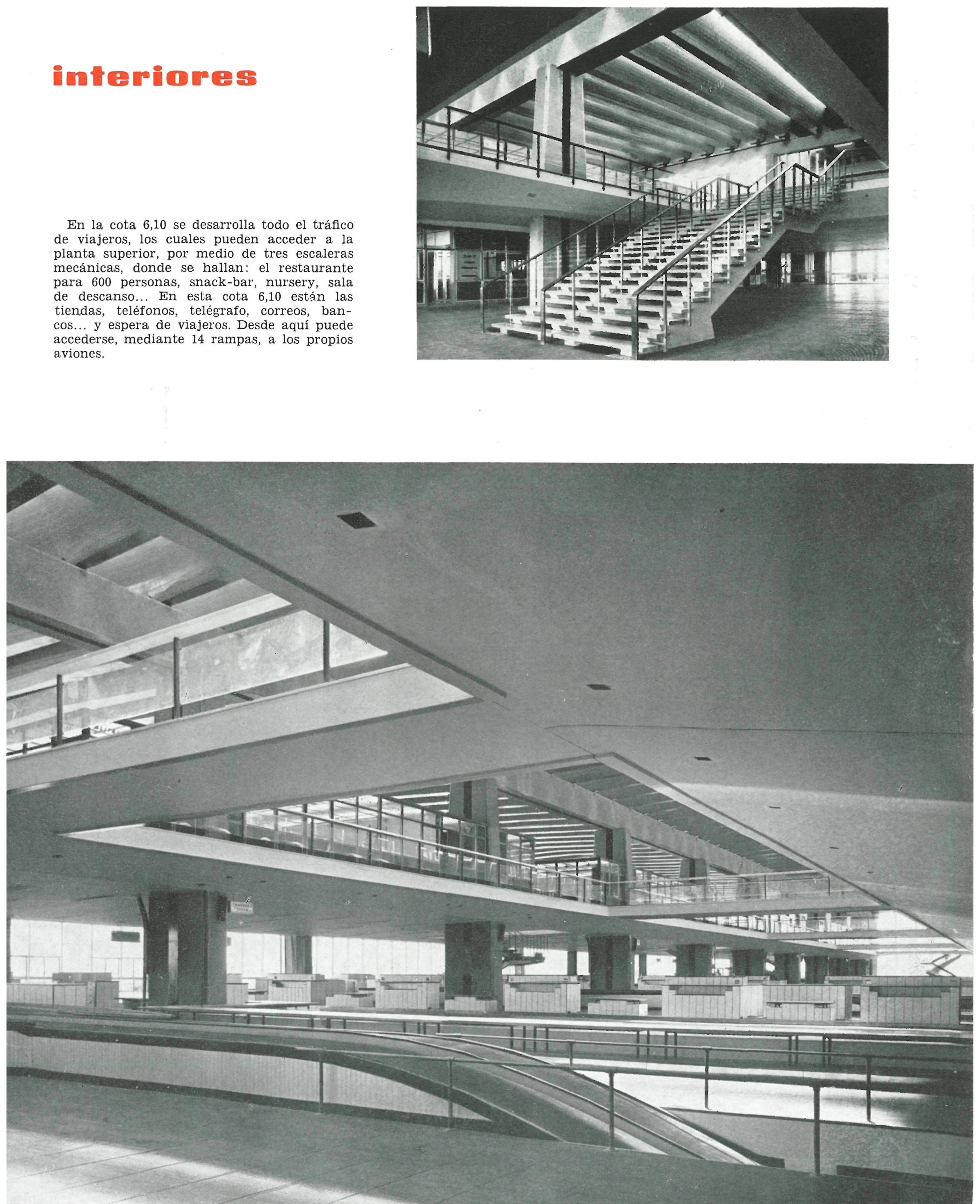


\section{Estruciura de la aeroestación}

Es, esencialmente, de hormigón armado.

La cubierta del salón es enteramente metálica; la de los cuerpos salientes hacia el campo, mixta, de hormigón y metálica.

Todas las estructuras se articulan según un esquema modular, con objeto de conseguir una distribución racional de todos los elementos. El módulo base es de $2,08 \mathrm{~m}$ entre ejes de los elementos secundarios, de lo cual se deriva una distribución regular, en malla, de 12,50 × 12,50 m para la disposición de pilares.

La cubierta del salón se ha realizado a base de nervios cortantes, con estructura celular en " $V$ ", sobre elementos de unión de hormigón armado. Esta disposición se acusa en la fachada principal.

La primera planta de los cuerpos salientes está constituída por una serie de nervios secundarios y elementos principales de elevada rigidez torsional, con objeto de absorber las complejas acciones transmitidas por la cubierta que, a su vez, está formada por una retícula metálica solidaria con la capa de tránsito de la terraza.

La aeroestación no está todavía totalmente terminada, ya que faltan algunas instalaciones y muchos detalles y mobiliario, que irán completándose según las disponibilidades económicas.

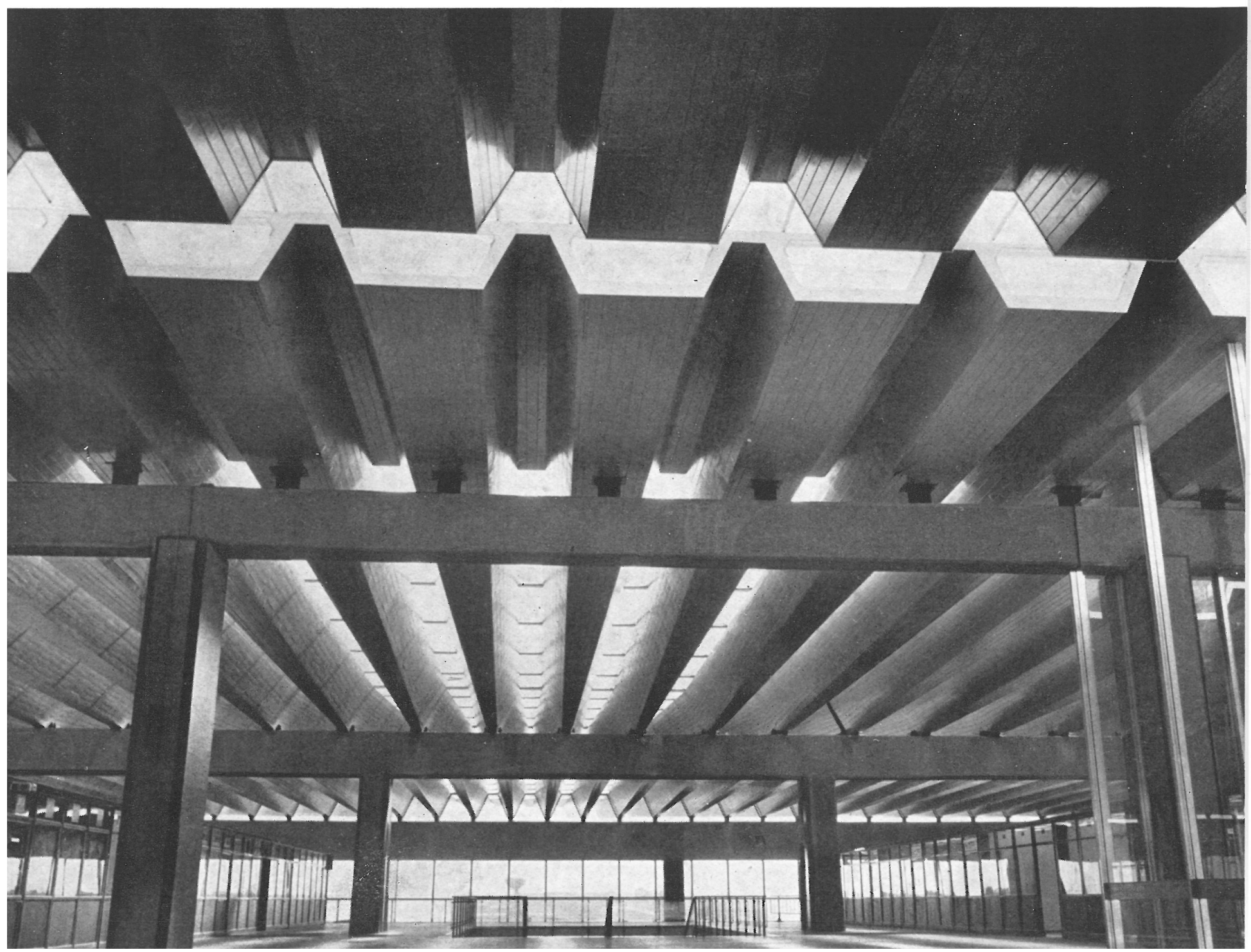

